\title{
Studi "Insitu Condition" Pengaruh Penambahan Fin Setengah Silinder yang Dimiringkan Sebagai Extended Surface dan Vortex Generator Terhadap Efisiensi Kolektor Surya Pemanas Udara
}

\author{
Harlista Dwi Oktyasworo dan Djatmiko Ichsani \\ Departemen Teknik Mesin, Fakultas Teknologi Industri, Institut Teknologi Sepuluh Nopember (ITS) \\ e-mail:djatmiko@me.its.ac.id
}

\begin{abstract}
Abstrak-Matahari merupakan energi yang terbesar di alam semesta. Energi yang diberikan oleh matahari berupa panas yang sangat ramah lingkungan, serta melimpah karena tidak akan pernah habis. Energi matahari sebagai sumber energy non konvensional dapat diaplikasikan pada kolektor pemanas udara yang berfungsi sebagai pengering. Penelitian ini dilakukan untuk mengetahui peforma kolektor surya jenis v-corrugated dengan penambahan obstacle dan fin berdiameter $6 \mathrm{~mm}$ yang dimiringkan sebesar $67,5^{\circ}$ pada insitu condition. Pengujian juga dilakukan dengan variasi laju alir massa sebesar $0,03 \mathrm{~kg} / \mathbf{s}$; $0,05 \mathrm{~kg} / \mathrm{s} ; 0,06 \mathrm{~kg} / \mathrm{s} ;$ dan $0,08 \mathrm{~kg} / \mathrm{s}$. Data diambil selama 5 hari dengan intensitas radiasi sesuai dengan kondisi di lapangan. Hasil yang didapatkan pada penelitian energi yang berguna yang dapat diserap oleh fluida berbanding lurus dengan peningkatan laju alir massa dan intensitas radiasi namun berbanding terbali $k$ dengan efisiensi kolektor. $Q_{\text {use }}$ tertinggi dicapai pada laju alir massa $0,06 \mathrm{~kg} / \mathrm{s}$ dengan intensitas radiasi $876 \mathrm{~W} / \mathrm{m}^{2}$ yakni sebesar $\mathbf{7 8 5 , 8 0}$ Watt. Sedangkan efisiensi tertinggi dicapai pada laju al ir massa $0,06 \mathrm{~kg} / \mathrm{s}$ dengan intensitas radiasi $654 \mathrm{~W} / \mathrm{m}^{2}$ yakni sebesar 94\%
\end{abstract}

Kata Kunci-efisiensi, fin, intensitas radiasi, kolektor, laju alir massa, obstacles, plat absorber.

\section{PENDAHULUAN}

$\mathrm{S}$ EIRING dengan pertumbuhan manusia yang semakin tinggi kebutuhan terhadap energipun semakin meningkat. Berdasarkan BPPT Indonesia Energy Outlook 2016, konsumsi energi final menurut jenisnya selama tahun 2000-2014 masih didominasi oleh BBM (bensin, minyak solar,minyak diesel, minyak tanah, minyak bakar, avtur dan avgas) dan semakin meningkat setiap tahunnya [1]. Oleh karena itu, renewable energy pun banyak diteliti agar mendapatkan efisiensi yang semakin baik sehingga dapat dimanfaatkan manusia. Energi surya merupakan salah satu sumber renewable energy yang ramah, murah, dan mudah didapatkan terutama di negara Indonesia yang terletak pada garis khatulistiwa. Energi surya dapat dikonversikan menjadi energi termal dalam suatu kolektor surya (solar collector) yang kemudian energi termal tersebut dapat digunakan untuk memanaskan air atau udara. Pada umumnya kolektor surya pemanas udara tersusun dari rangka, cover glass, dan absorber berbentuk datar. Namun modifikasi selalu dilakukan untuk mendapatkan kolektor dengan efisiensi yang baik. Salah satu penelitian yang menggabungkan antara menggabungkan plat absorber berbentuk v-corrugated dan diberi tambahan obstacle yaitu dilakukan oleh Ekadewi,dkk [2]. Pada penelitian kali ini, modifikasi yang dilakukan adalah berpedoman pada modifikasi yang telah dilakukan Ekadewi pada 2014 yaitu dengan menggunakan v-corrugated plat absorber dengan penambahan obstacle berbentuk paruh $30^{\circ}$ di sepanjang saluran serta akan ditambahkan fin pada plat absorber sebagai extended surface untuk memperluas luasan perpindahan panas. Fin yang digunakan pada penelitian ini berdasarkan penelitian yang telah dilakukan sebelumnya. Clarisa dan Alifia melakukan studi eksperimental dengan menggunakan fin berbentuk prisma segitiga dengan lebar $3 \mathrm{~mm}$ yang diaplikasikan pada lpat absorber tipe v-corrugated [3][4]. Sedangkan Fajar dan Bernardus melakukan eksperimen penambahan fin berbentuk setengah silinder berdiameter $6 \mathrm{~mm}$ yang dipasang pada bagian bawah kolektor surya [5][6]. Dari hasil penelitian tersebut didapatkan bahwa fin dengan efisiensi terbaik secara eksperimen dicapai oleh modifikasi fin berbentuk setengah silinder berdiameter $6 \mathrm{~mm}$ yang dimiringkan $67,5^{\circ}$ dengan jarak $0,75 \mathrm{~L}$ dari obstacle. Oleh karena itu modifikasi fin dan obstacles tersebut yang digunakan pada penelitian ini untuk memberikan hasil lebih baik terhadap efisiensi kolektor surya.

\section{URAIAN PENELITIAN}

\section{A. Kolektor Surya}

Kolektor surya merupakan alat yang mampu merubah energi radiasi matahari menjadi energi panas dengan cara menyerap panas matahari yang selanjutnya panas tersebut digunakan untuk memanaskan fluida kerja dan kemudian dikonversikan menjadi energi. Suatu kolektor surya pada dasarnya terdiri dari plat absorber, kaca penutup (cover glass) transparan yang dipasang di atas plat absorber agar meminimalisir kehilangan kalor secara konveksi dan radiasi ke atmosfer, serta isolasi di bagian bawah dan samping kiri kanan untuk mengurangi kehilangan kalor secara konduksi. 


\section{B. Overall Heat Transfer Coefficient}

Overall Heat Transfer Coefficient File $\left(\mathrm{U}_{\mathrm{L}}\right)$ erat kaitannya dengan tahanan thermal [7]. Secara umum, konsep tahanan thermal pada kolektor surya ini dapat digambarkan sebagai berikut:

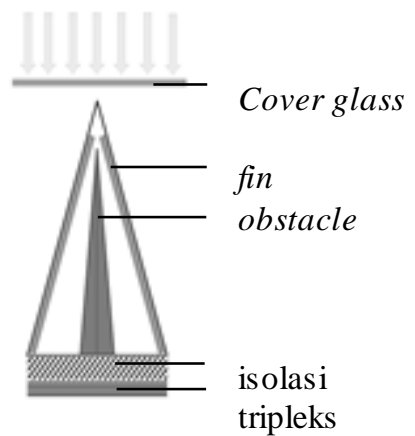

(a)

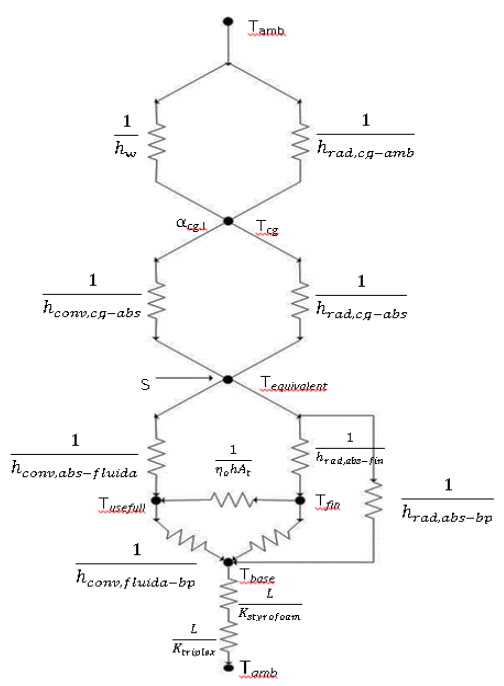

(b)

Gambar 1. (a) Bagian-bagian pada kolektor dan (b) Skema tahanan thermal kolektor surya $v$-corrugated dengan fin dan obstacle.

Selanjutnya akan dihitung $\mathrm{U}_{\mathrm{Top}}$ dan $\mathrm{U}_{\text {bottom }}$ dengan persamaan:

$$
\begin{aligned}
U_{T} & =\frac{1}{\frac{1}{h_{w}}+\frac{1}{h_{r, c g-a m b}}+\frac{1}{h_{c o n v, c g-a b s}}+\frac{1}{h_{r, c g-a b s}} \times A_{a b s}} \\
U_{B} & =\frac{1}{\left(\frac{L_{1}}{k_{1}}+\frac{L_{2}}{k_{2}}+\frac{1}{h_{w}}\right) \times A_{i s o}}
\end{aligned}
$$

Sehingga dapat diketahui nilai $\mathrm{U}_{\mathrm{L}}$ adalah:

dimana:

$$
U_{L}=U_{T}+U_{B}
$$

$\mathrm{U}_{\mathrm{L}}=$ overall heat coefficient $\left(\mathrm{W} / \mathrm{m}^{2} . \mathrm{K}\right)$

\section{Energi Berguna Kolektor Surya $\left(Q_{u s e}\right)$}

Energi berguna yang dapat diserap oleh kolektor surya dapat diketahui dari persamaan [2]:

$$
Q_{u}=\dot{m} C_{p}\left[T_{f, \text { out }}-T_{f, \text { in }}\right]
$$

atau

$$
Q_{u}=A_{c} \cdot F_{R}\left[S-U_{L}\left(T_{f, i n}-T_{a m b}\right)\right]
$$

$$
S=1,01 x \tau_{c g} x \alpha_{a b s} x I_{T}
$$

dimana:

$\mathrm{Q}_{\mathrm{u}} \quad=$ energi berguna (Watt)

$\mathrm{S} \quad=$ radiasi matahari per satuan luas yang $\operatorname{diserap}\left(\frac{W}{m^{2}}\right)$

$\mathrm{U}_{\mathrm{L}}=$ koefisien kehilangan panas total $\left(\frac{\mathrm{W}}{\mathrm{m}^{2} \cdot \mathrm{K}}\right)$

$\mathrm{T}_{\mathrm{f}, \mathrm{in}}=$ temperatur fluida masuk ducting channel $(\mathrm{K})$

$\mathrm{T}_{\mathrm{amb}}=$ temperatur lingkungan $(\mathrm{K})$

$\mathrm{T}_{\mathrm{u}} \quad=$ temperatur usefull equivalent $(\mathrm{K})$

$\mathrm{T}_{\mathrm{abs}}=$ temperatur plat absorber $(\mathrm{K})$

$\mathrm{T}_{\text {base }}=$ temperatur plat bawah $(\mathrm{K})$

$\mathrm{T}_{\text {fin }}=$ temperatur fin $(\mathrm{K})$

$\mathrm{F}_{\mathrm{R}}=$ collector heat removal factor

$\tau_{\mathrm{cg}}=$ transmisivitas cover glass

$\alpha_{\mathrm{abs}}=$ absorbsivitas plat absorber

\section{Efisiensi Kolektor Surya}

Efisiensi merupakan representatif dari unjuk kerja kolektor surya. Efisiensi dapat diketahui dengan persamaan:

$$
\boldsymbol{\eta}=\frac{\mathbf{Q}_{\mathbf{u}}}{\mathrm{A}_{\mathrm{abs}} \cdot \mathbf{I}_{\mathbf{T}}} \times \mathbf{1 0 0} \%
$$

dimana:

$$
\begin{array}{ll}
\eta & =\text { efisiensi kolektor surya } \\
\mathrm{Q}_{u} & =\text { energi berguna (Watt) } \\
\mathrm{A}_{a b s} & =\text { luasan efektif kolektor }\left(\mathrm{m}^{2}\right) \\
\mathrm{I}_{\mathrm{T}} & =\text { Intensitas radiasi matahari }\left(\frac{W}{\mathrm{~m}^{2}}\right)
\end{array}
$$

\section{E. Penurunan Tekanan pada Kolektor Surya}

Pada saluran kolektor surya tekanan aliran diasumsukan incompressible fluid yang mengalir pada pipa atau duct. Pada kenyataannya, aliran dalam pipa atau duct mengalami pengaruh gesekan yang signifikan karena alirannya turbulen. Sehingga persamaan Bernoulli tidak dapat diaplikasikan. Pengaruh gesekan akan menyebabkan penurunan nilai pada persamaan Bernoulli (tidak konstan).

Untuk aliran turbulen, penurunan tekanan tidak dapat dihitung secara analitis melainkan eksperimental. Pada aliran fully developed, penurunan tekanan dipengaruhi oleh gesekan pada saluran horizontal dengan luas area konstan, yaitu diameter (D), panjang saluran (L), kekasaran permukaan (e), kecepatan rata-rata aliran $(\bar{V})$, massa jenis fluida $(\rho)$, dan viskositas fluida $(\mu)$. Maka koefisien friksi aliran dapat dicari dengan persamaan :

$$
f=\frac{\Delta P}{\frac{L}{D_{h}} \rho \frac{V^{2}}{2}}
$$

\section{METODE PENELITIAN}

\section{A. Pengujian Eksperimental Kolektor Surya}

Eksperimen ini dilakukan pada kolektor surya $v$-corrugated dengan obstacle berbentuk paruh dengan sudut $30^{\circ}$. Pada kolektor surya tersebut akan ditambahkan fin setengah silinder berdiameter $6 \mathrm{~mm}$ yang dimiringkan dengan sudut kemiringan $66,7^{\circ}$ untuk memperluas bidang perpindahan panas serta sebagai vortex generator yang melalui laluan. Kolektor akan 
diuji dengan variasi laju alir massa yang besarnya $0.03 \mathrm{~kg} / \mathrm{s}$; $0.05 \mathrm{~kg} / \mathrm{s} ; 0.06 \mathrm{~kg} / \mathrm{s}$ dan $0.08 \mathrm{~kg} / \mathrm{s}$. Penelitian ini difokuskan pada hasil trend grafik yang terjadi saat pengujian langsung pada kondisi lapangan atau disebut dengan insitu condition. Penelitian eksperimental kolektor surya V-corrugated absorber dengan obstacle dan penambahan fin dilaks anakan di Roooftop Gedung Departemen Teknik Mesin, Institut Teknologi Sepuluh Nopember Surabaya.

Skema perlatan yang digunakan dalam eksperimen ini dapat dilihat pada Gambar 2 dibawah ini:

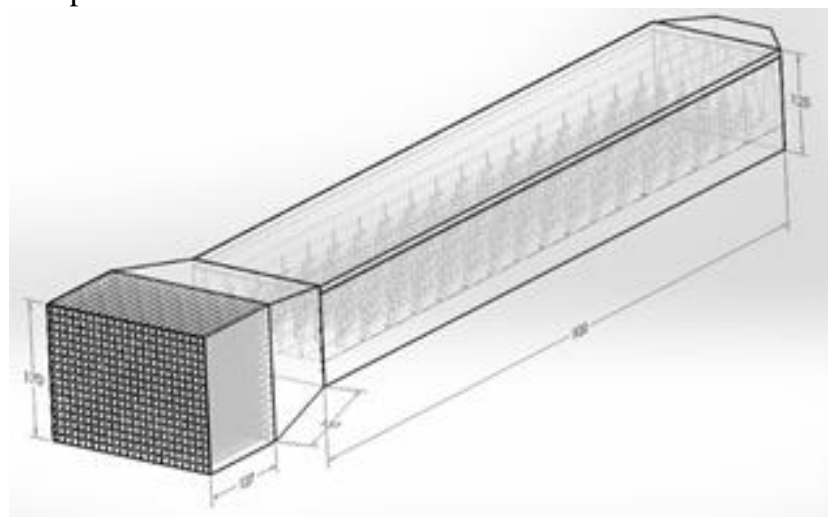

(a)

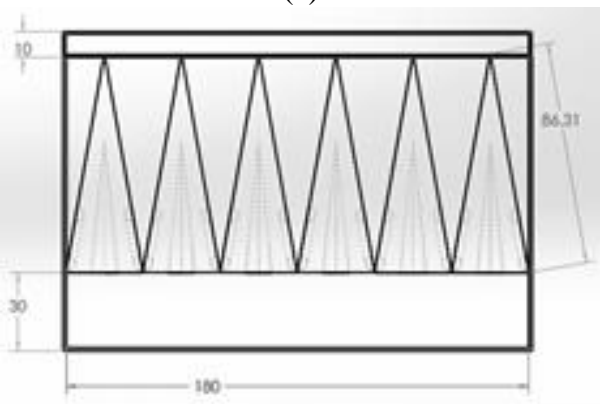

(b)

Gambar 2. (a) Skema peralatan eksperimen kolektor surya dengan 6 laluan (b) Skema peralatan tampak depan.

Gambar 2 (a) dan (b) merupakan skema kolektor yang akan digunakan pada eksperimen. Didalan kolektor terdapat enam laluan v-corrugated absorber plate dengan penambahan fin dan obstacles disetiap laluannya. Penambahan tersebut bertujuan untuk menambah efek olakan terhadap aliran yang masuk pada laluan kolektor surya. Ada beberapa titik pengukuran suhu yang akan diambil sebagai acuan perhitungan. Titik-titik tersebut dapat dilihat pada gambar 3 dibawah ini.

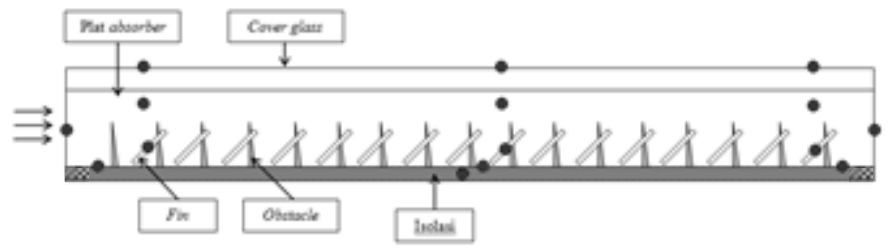

Gambar 3. Penempatan thermal sensor pada salah satu laluan.

Gambar diatas merupakan posisi peletakan thermal sensor yang akan disambungkan dan dibaca oleh controller arduino. Pemasangan thermal sensor akan diletakkan pada 2 laluan untuk mendapatkan temperatur rata-rata yang baik dari kedua laluan. Untuk keseluruhan pengambilan data temperature terdapat 24 titik pengambilan data.

\section{HASIL DAN PEMBAHASAN}

\section{A. Analisa Energi Berguna pada Kolektor Surya}

Dari pengujian yang telah dilakukan, didapatkan data-data yang akan digunakan untuk menghitung energi berguna serta efisiensi dari kolektor surya sebagai representatif unjuk kerja kolektor surya tersebut. Energi berguna dapat dihitung menggunakan persamaan termodinamika dan perpindahan seperti yang telah dijelaskan sebelumnya. Pada nilai $\mathrm{Qu}$ thermo dan $\mathrm{Qu}_{\text {perpan }}$ hasil perhitungan terdapat selisih yang cukup besar. Perbedaan ini dikarenakan dalam melakukan perhitungan secara perpindahan panas terdapat banyak asu ms i yang digunakan seperti faktor pelepasan panas, $F_{R}$, dan koefisien absorbsivitas plat penyerap dan transmisivitas kaca dalam menghitung jumlah intensitas radiasi yang diterima kolektor surya (S), serta asumsi dalam perhitungan overall heat coefficient total ( $\mathrm{U}_{\mathrm{L}}$ ) sehingga hasil yang didapatkan kurang mendekati kondisi aktual (eksperimen). Dengan demikian, nilai Quse yang digunakan didasarkan pada perhitungan energi berguna secara desain (termodinamika) yaitu, $Q_{u}=\dot{\boldsymbol{m}} \boldsymbol{C}_{\boldsymbol{p}}\left[\boldsymbol{T}_{\boldsymbol{f}, \mathrm{out}}-\boldsymbol{T}_{\boldsymbol{f}, \boldsymbol{i n}}\right]$.

Persamaan tersebut secara langsung menghubungkan pengaruh variasi laju alir massa dengan intensitas radiasi pada insitu condition. Semakin besar m (laju alir massa) yang melalui ducting (laluan) maka semakin besar pula nilai $\mathrm{Quse}_{\mathrm{u}}$ yang dihasilkan, seiring dengan peningkatan intensitas radiasinya seperti yang dapat terlihat dari gambar 4 dibawah.

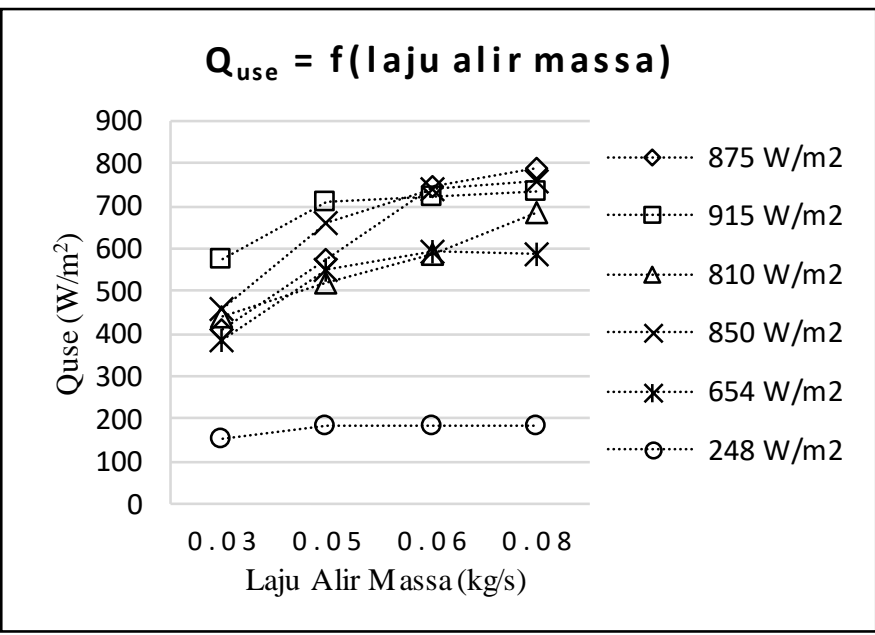

Gambar 4. Grafik Quse fungsi laju alir massa pada tiap intesitas radiasi.

Nilai $\mathrm{Qu}_{\text {thermo merupakan }} \mathrm{Q}_{\mathrm{use}}$ actual yang terkur saat percobaan. Quse tertinggi dihasilkan pada laju aliran massa $0.08 \mathrm{~kg} / \mathrm{s}$ dengan intensitas radiasi $875 \mathrm{~W} / \mathrm{m}^{2}$, yakni sebesar 785.80 Watt. Perhitungan $\mathrm{Qu}_{\text {thermo }}$ dipengaruhi oleh besar laju aliran massa dan beda temperatur yang dihasilkan. Pada intensitas radiasi yang sama, semakin kecil laju aliran massa yang dialirkan maka semakin mudah fluida kerja untuk menyerap panas dan menghasilkan beda temperatur yang besar. Namun, ketika beda temperatur besar tetapi laju aliran massa kecil maka nilai $\mathrm{Qu}_{\text {thermo }}$ yang didapatkan kecil. 


\section{B. Analisa Overall Heat Coefficirnt Total $\left(U_{L}\right)$}

Overall heat coefficient sangat erat kaitannya dengan thermal resistance. Semakin kecil nilai thermal resistance ( $\mathrm{R}_{\text {total }}$ ) maka akan semakin besar total $\mathrm{U}_{\mathrm{L}}$. selain itu, hubungan $\mathrm{U}_{\mathrm{L}}$ juga dapat dilihat berdasakan persamaan $\mathrm{Q}_{\mathrm{use}}$ yaitu:

$$
\frac{Q u}{A c}=\operatorname{Fr}\left(S-U_{L}\left(T_{f, \text { in }}-T_{a m b}\right)\right)
$$

atau,

$$
\frac{Q u}{A c I_{T}}=\left(F r \tau_{c g} \alpha_{a b s}-U_{L} F r \frac{\left(T_{f, i n}-T_{a m b}\right)}{I_{T}}\right)
$$

sehingga menurut persamaan tersebut dapat dibentuk suatu fungsi x dengan variabel pengubah yaitu $\frac{\Delta T}{I_{T}}$. Intensitas yang selalu berubah-ubah setiap waktu sangat mempengaruhi ambient temperature disekitarnya pula. Oleh karena itu dari perhitungan $\mathrm{U}_{\mathrm{L}}$, dapat ditarik nilai suatu regresi seperti terlihat pada gambar 5 dibawah ini.

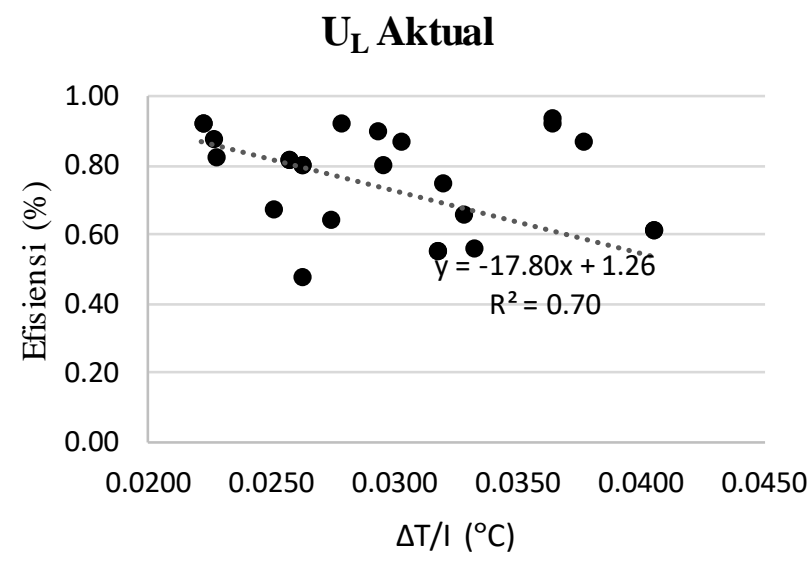

Gambar 5. Grafik $\Delta \mathrm{T} / \mathrm{I}_{\mathrm{T}}$ terhadap Efisiensi pada seluruh variasi intensitas radiasi.

Trendline Grafik perbandingan $U_{L}$ terhadap laju aliran massa pada semua variasi intensitas menunjukkan penurunan. Berdasarkan gambar 5 besarnya nilai $\mathrm{UL}_{\mathrm{L}}$ berbanding terbalik dengan fungsi $\Delta \mathrm{T} /$ IT. Nilai $\mathrm{U}_{\mathrm{L}}$ didapatkan dari slope (kemiringan) yang dihasilkan dari pengambilan data saat percobaan. Hasil yang didapatkan menunjukan adannya fungsi yang berlawanan arah atau semakin menurun dengan $\mathrm{R}^{2}$ yang mendekati satu sehingga kecocokan data dikatakan lebih baik. Dari persamaan regresi tersebut dapat diketahui bahwa nilai $\mathrm{UL}_{\mathrm{L}}$ aktual yang didapatkan adalah sebesar 0,7 dan menghasilkan nilai $\mathrm{F}_{\mathrm{r}} \mathrm{U}_{\mathrm{L}}$ dari regresi adalah sebesar 17,80.

\section{Analisa Efisiensi pada Kolektor Surya}

Efisiensi merupakan perbandingan antara energi yang berguna $\left(\mathrm{Q}_{\mathrm{use}}\right)$ dengan energi yang masuk. Nilai efisiensi ini menunjukkan baik atau tidaknya kolektor surya dalam mentransfer energi panas ke fluida kerja yang berupa udara. Dari data yang te;ah didapatkan dan diolah efisiensi kolektor surya sesuai dengan persamaan $\eta=\frac{Q_{u s e t h e r m o}}{A_{c} \cdot I_{T}}$ bahwa efisiensi terbaik adalah pada intensitas radiasi yang rendah meskipun pada $Q_{u s e}$ yang tertinggi. Hal ini dapat dijelaskan berdasarkan perumusan efisiensi, jika dijabarkan yaitu $\eta=1-\frac{Q \text { loss }}{A_{c} \cdot I_{T}}$ dimana $Q_{\text {loss }}=A_{c} \cdot\left[U_{T}\left(T_{a b s}-T_{a m b}\right)\right], \quad$ semakin kecil intensitas radiasi maka beda temperatur plat penyerap dan udara sekitar semakin kecil pula. Namun pada eksperimen ini efisiensi tertinggi tidak dicapai pada intensitas yang paling

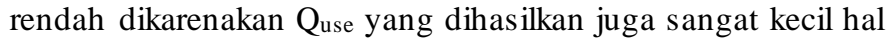
tersebut dapat terjadi karena kurang akuratnya pada saat pengukuran sehingga terjadi penyimpangan data. Trend efisiensi kolektor surya dapat dilihat pada gambar 6 dibawah ini.

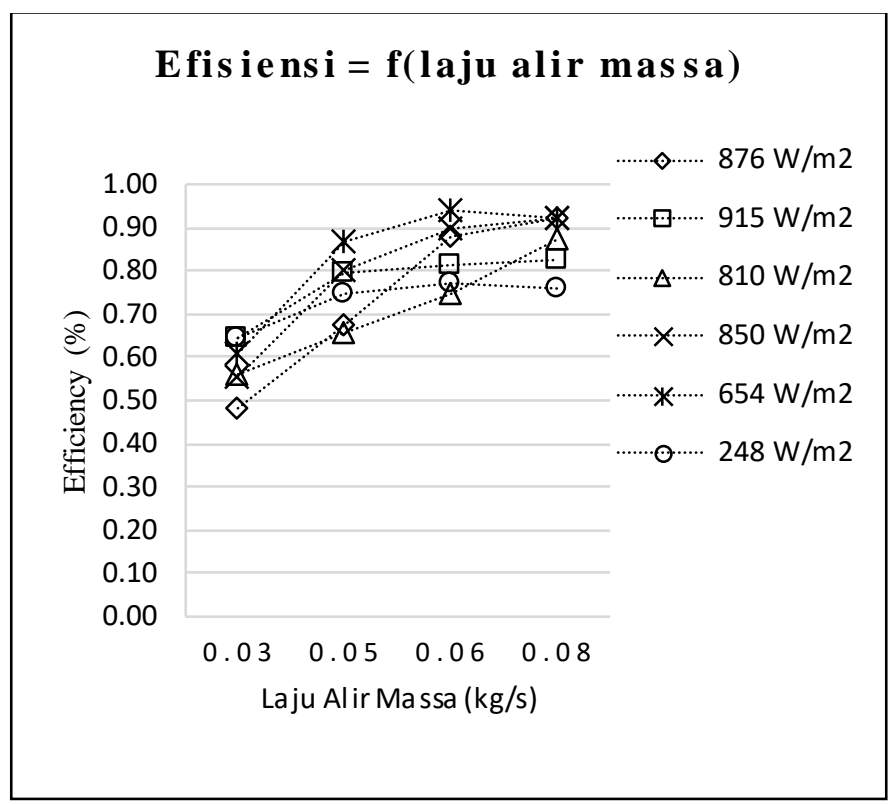

Gambar 6. Effisiensi aktual (termodinamika) pada variasi intensitas radiasi.

Gambar 6 merupakan trend grafik perbandingan efisiensi terhadap laju aliran massa terus meningkat seiring dengan bertambahnya laju aliran massa. Nilai efisiensi ini menunjukkan baik atau tidaknya kolektor surya dalam mentransfer energi panas ke fluida kerja yang berupa udara. Pada hasil pengujian dapat dilihat efisiensi tertinggi sebesar 0,94 dicapai pada laju aliran massa $0,06 \mathrm{~kg} / \mathrm{s}$ dengan intensitas $654 \mathrm{Watt} / \mathrm{m}^{2}$.

Efisiensi dipengaruhi oleh overall heat coefficient top $\left(\mathrm{U}_{\mathrm{T}}\right)$. Pada perhitungan overall heat coefficient top $\left(\mathrm{U}_{\mathrm{T}}\right)$ dipengaruhi oleh temperatur plat penyerap dan kaca penutup. Semakin kecil intensitas radiasi maka $U_{T}$ semakin kecil dan Quse energi surya semakin besar dengan demikian efisiensi yang dihasilkan menjadi besar saat intensitas radiasi rendah. Namun, pada hasil penelitian terdapat penyimpangan karena efisiensi tertinggi pada intensitas terendah kedua. Hal tersebut dapat terjadi karena pada intensitas terendah $\mathrm{Q}_{\mathrm{use}}$ yang dihasilkan juga sangat kecil.

\section{Penurunan Tekanan dan Koefisien Friksi Aliran Udara}

Penurunan tekanan adalah hasil dari gaya gesek pada fluida ketika mengalir melalui saluran sehingga kecepatan aliran fluida sangat berpengaruh pada perubahannya. Penurunan tekanan pada pengujian ini diukur dengan menggunakan differential magnetic pressure gage selama proses pemanasan pada kodisi lapangan pada tiap variasi Reynolds Number. Dengan mengetahui panjang saluran udara (L) dan kecepatan udara (v), koefisien friksi aliran dapat dicari dengan menggunakan persamaan yakni, $\mathrm{f}=\frac{\Delta \mathrm{P}}{\frac{\mathrm{L}}{\mathrm{D}_{\mathrm{h}}} \rho \frac{\mathrm{V}^{2}}{2}}$. 


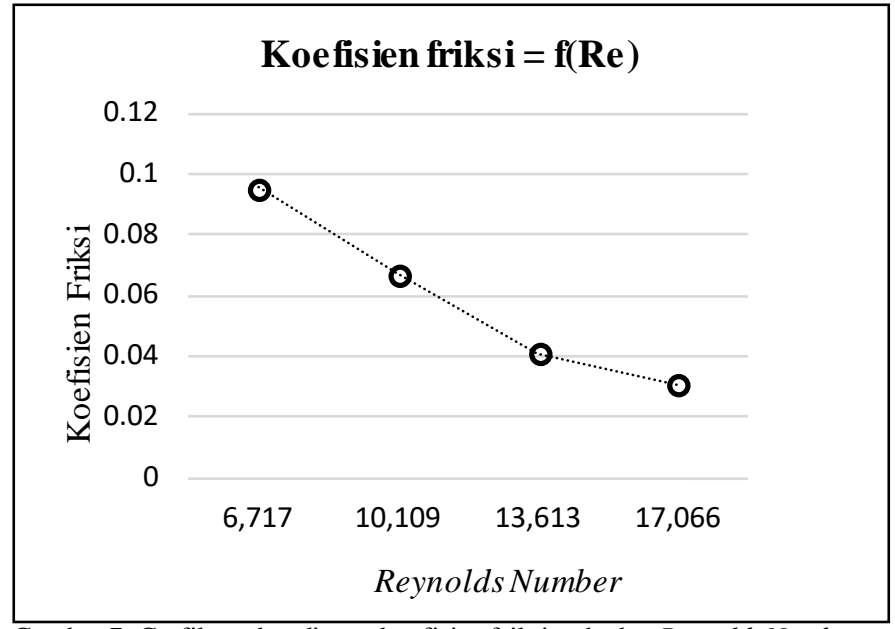

Gambar 7. Grafik perbandingan koefisien friksi terhadap Reynolds Number.

Gambar 7 merupakan grafik koefisien friksi aliran (f) fungsi Reynolds number $(\mathrm{Re})$ pada intensitas $915 \mathrm{~W} / \mathrm{m}^{2}$. Dari grafik dapat diketahui koefisien friksi tertinggi pada Reynolds number 6717 dan terendah pada Reynolds number 17066. Tren pada grafik menurun meunjukkan koefisien friksi aliran berkurang seiring bertambahnya Re, hal ini bersesuaian dengan Moody Diagram (Introduction to Fluid Mechanics, Fox). Besarnya Reynolds number sebanding dengan kecepatan aliran (v). Saat aliran laminar ( $\operatorname{Re} \leq 2300$ ), nilai koefisien gesek dipengaruhi oleh Reynolds number dan kekasaran permukaan saluran (roughness, e/D), sehingga semakin besar Reynolds number mengakibatkan semakin kecil nilai koefisien gesek. Sedangkan saat aliran turbulen $(\operatorname{Re}>2300)$, nilai $\mathrm{f}$ cenderung konstan terhadap kenaikan Reynolds number.

\section{KESIMPULAN DAN SARAN}

Berdasarkan penelitian yang telah dilakukan pada kolektor surya $v$-corrugated absorber plate dengan penambahan obstacle dan fin berbentuk setengah silinder yang dimiringkan dapat ditarik kesimpulan sebagai berikut:

1. Berdasarkan hasil eksperimen, didapatkan Quse paling tinggi pada laju aliran massa sebesar $0.08 \mathrm{~kg} / \mathrm{s}$ dengan intensitas radiasi $875 \mathrm{Watt} / \mathrm{m}^{2}$ yakni $785.80 \mathrm{~W}$ att.

2. Berdasarkan persamaan regresi diketahui bahwa nilai $\mathrm{U}_{\mathrm{L}}$ (overall heat coefficient total) pada kondisi aktual memiliki trendline grafik menurun terhadap fungsi $\Delta \mathrm{T} / \mathrm{I}_{\mathrm{T}}$. Nilai $\mathrm{F}_{\mathrm{r}} \mathrm{U}_{\mathrm{L}}$ yang didapatkan adalah sebesar 17.80 dengan $\mathrm{R}^{2}$ sebesar 0,7 .

3. Efisiensi paling tinggi yakni $94 \%$ dicapai pada laju aliran massa $0,06 \mathrm{~kg} / \mathrm{s}$ dengan intensitas radiasi sebesar 654 $\mathrm{Watt} / \mathrm{m}^{2}$.

4. Penurunan tekanan berbanding lurus dengan penambahan Reynolds Number. Penurunan tekanan paling kecil dicapai pada Reynolds number 6717 yakni 43 Pascal sedangkan penurunan tekanan paling besar ada pada Reynolds number 17066 yakni 86 Pascal.

Adapun saran yang dapat dilakukan pada penelitian selanjutnya agar peforma kolektor lebih baik dari sebelumnya, antara lain:
1. Pengukuran dilakukan dengan peralatan yang lebih sensitive agar holding time pengambilan data tidak terlalu lama.

2. Pemasangan alat ukur lebih sistematis agar tidak mengganggu aliran.

3. Mempelajari karakteristik penggunaan kaca biasa dan tempered glass dan pengaruh lebar celah antara plat penyerap dan kaca penutup.

4. Penambahan laju alir massa yang melewati ducting agar mendapatkan hasil kurva Quse yang optimal.

\section{LAMPIRAN}

Lampiran 1: Setting alat ukur yang diterapkan pada saat pengambilan data.

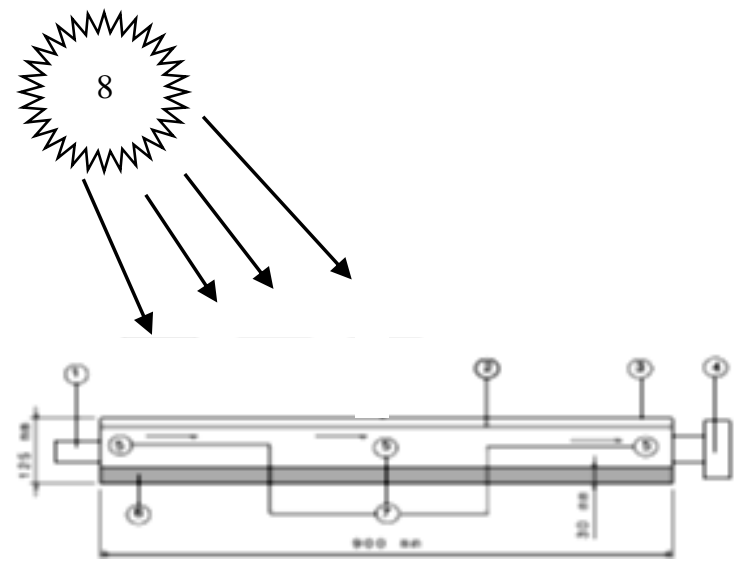

Keterangan:

1. Contraction and honey comb

2. Plat absorber

3. Cover glass

4. Blower

5.Thermocouple

6.Isolator

7.Thermocouple display

8.Matahari

Lampiran 2: Gambar alat yang digunakan pada eksperimen.

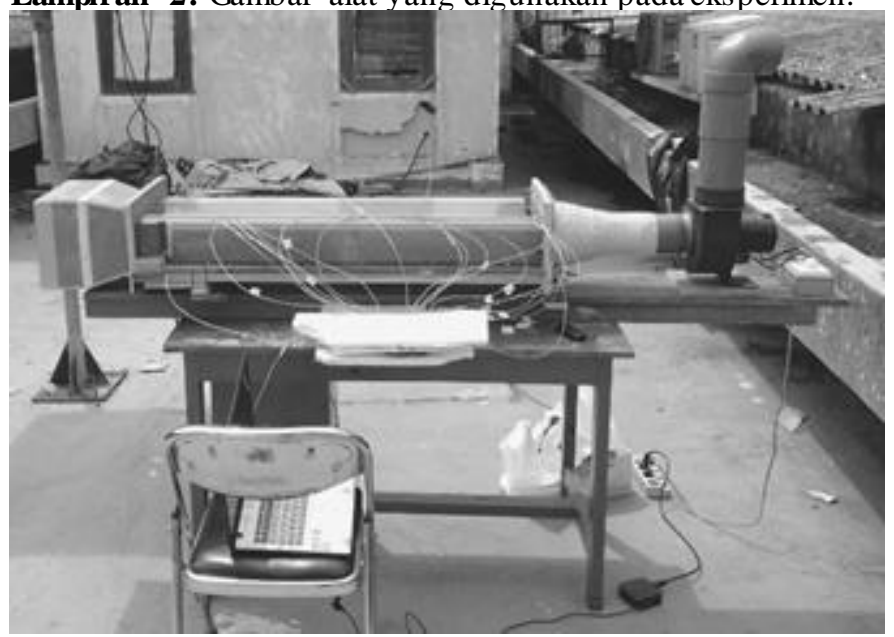

\section{DAFTAR PUSTAKA}

[1] U. Priyanto, "Outlook Energi Indonesia," Jakarta, 2015.

[2] E. A. Handoyo, "Peningkatan Kinerja Kolektor Surya Tipe VCorrugated Absorber Plate Menggunakan Obstacle yang Dit ekuk Secara Vertikal," Surabaya, 2014.

[3] C. Suroso, "Studi Simulasi Numerik dan Eksperimental Pengaruh Penambahan Fin Berbentuk Prisma Segitiga Tegak Lurus Aliran yang Dipasang pada Bagian Bawah Plat Absorber Berbentuk V 
Terhadap Efisiensi Kolektor Surya Pemanas Udara," Surabaya, 2016.

[4] A. H. Masitha, "Studi Simulasi Numerik dan Eksperimental Pengaruh Penambahan Fin Prisma Segitiga yang Dimiringkan Terhadap Arah Aliran yang Dipasang pada Bagian Bawah Plat Absorber Berbentuk VTerhadap Efisiensi Kolektor Surya Pemanas Udara," Surabaya, 2016.

[5] F. S. P. Lestari, "Studi Simulasi Numerik dan Eksperimental Pengaruh Penambahan Fin Berbentuk Setengah Silinder Tegak Lurus Aliran yang Dipasang pada Bagian Bawah Plat Absorber Berbentuk V Terhadap Efisiensi Kolektor Surya Pemanas Udara, "
Surabaya, 2016.

[6] B. Pualam, "Studi Simulasi Numerik dan Eksperimental Pen garuh Penambahan Fin Berbentuk Setengah Silinder yang Dimirin gkan Terhadap Arah Aliran yang Dipasang pada Bagian Bawah Plat Penyerap Berbentuk VTerhadap Efisiensi Kolektor Surya Pemanas Udara," Surabaya, 2017.

[7] F. P. I. and D. P. Dewitt, Fundamentals of Heat and Mass Transfer 6th Edition. United State of America: JOHN WILEY \& SONS, 2007. 